\title{
Vaivenes de un tópico: la contraposición corte y aldea en el último Lope de Vega*
}

\section{Ups and Downs of a Topic. The Contrast between Court and Village in the Last Lope de Vega}

\author{
Esperanza Rivera Salmerón \\ Universidad de Valladolid \\ esperanzamaria.rivera@uva.es \\ ORCID iD: https://orcid.org/0000-0001-9656-9979
}

\section{RESUMEN}

El menosprecio de corte y la alabanza de aldea es un leit motiv en varias de las comedias del Lope de senectud. En ellas vemos cómo ambos espacios se cargan de un peculiar significado y cómo reflejan simbólicamente siempre las mismas ideas, aquellas que la tradición ha consagrado: la corte es el lugar de la envidia, del engaño, del poder; mientras que la aldea lo es de la paz, de la transparencia, del amor sin ataduras sociales, del locus amoenus. Ejemplo de ello son las comedias palatinas Del monte sale quien al monte quema, La boba para los otros y discreta para sí, Porfiando vence amor, La mayor virtud de un rey o iSi no vieran las mujeres! Estudiaremos sus personajes, sus argumentos, sus versos..., y nos detendremos fundamentalmente en sus esquemas dramáticos para intentar explicar por qué estos lugares literarios se convierten en una obsesión del último Lope.

Palabras Clave: Lope de Vega; senectute; teatro; tópico; corte; aldea; beatus ille.

\section{ABSTRACT}

The disapproval of the court and praise for the village is a leit motiv in elderly Lope de Vega's several comedies. There we can see how both spaces have a peculiar meaning, and how they always reflect symbolically the same ideas, established by the tradition: while the court represents envy, deception and power, the village is a symbol of peace, transparency, free love, a locus amoenus. Good examples of it are the palatine comedies Del monte sale quien al monte quema, La boba para los otros y discreta para sí, Porfiando vence amor, La mayor virtud de un rey o iSi no vieran las mujeres! We will study their characters, their plots, their verses. We will

${ }^{*}$ Este artículo se publica en el marco del Proyecto de Investigación De Antonio Enríquez Gómez a Fernando de Zárate: obra dramática y ensayos políticos (FFI2017-87523-P), financiado por el Ministerio de Ciencia, Innovación y Universidades. 
stop essentially in their dramatic structures to try to figure out why these literary spaces turn into an obsession for the last Lope.

Key words: Lope de Vega; Senectute; Theater; Topic; Court; Village; Beatus ille.

La corte, vana y pomposa, es cárcel de oro labrada, que en ser prisión es pesada, $y$ por ser de oro sabrosa ${ }^{1}$.

El tópico de «menosprecio de corte y alabanza de aldea» tiene su origen, como tantos otros, en la literatura grecolatina. En este caso es fácil pensar, fundamentalmente, en el Epodo segundo de Horacio y en las Geórgicas (II, 458 y siguientes) de Virgilio como pioneros en la ruptura de estos mundos que aparecerán contrapuestos a partir de entonces en la literatura y que se concretarán en el famoso y reiterado beatus ille del texto horaciano. Ambos poetas vieron en el campo un lugar de soledad, reflexión y paz, lo que les llevó a exaltar ese «bucolismo» o «georgismo» que hemos de entender en su relación directa con «las condiciones económicas, políticas e ideológicas de la Italia de aquel entonces» (Salomon 1985: 157), es decir, con «el mundanal ruido» que reinaba en la capital romana.

El hombre de corte de finales del XV y principios del XVI vive en sus propias carnes ese anhelo de evasión del ambiente ambicioso, adulador y exigente que lo rodea y encuentra en los citados poetas latinos un referente vital que será reflejado en el mundo literario bajo la pluma de algunos de esos nobles. Sabemos que en la literatura española destacan, en el recurso a este tópico, el marqués de Santillana o Juan del Encina en el siglo XV, pero de una manera aún muy esporádica y poco desarrollada. El hito lo marca Antonio de Guevara, ya a comienzos del XVI, con su Menosprecio de corte y alabanza de aldea ${ }^{2}$, de 1539. Esta pieza es considerada clave para el florecimiento de un tópico que será capital a lo largo de los Siglos de Oro (y hasta el siglo XVIII). Como ha estudiado Redondo ${ }^{3}$ (1979a), el beatus ille horaciano se reactualiza con Gue-

${ }^{1}$ Emblema «Los cortesanos» de Alciato (2003: 146).

2 Para un estudio detallado de la obra véase la edición de Márquez Villanueva 1998.

3 Por lo que respecta a las fuentes del tópico reelaborado por Guevara, véanse en el citado estudio de Redondo (1979a: 253-254). En cuanto a la influencia del texto guevariano en siglos posteriores, y el poco conocimiento que se tuvo de él hasta la segunda mitad del siglo XVII (1657), consúltese Redondo 1979b. No obstante, es clara su influencia en Cristóbal de Castillejo, Cervantes, Lope y su teatro, Góngora... (como indica, por ejemplo, Márquez Villanueva 1998: 162), lo que nos hace pensar que la reflexión de Guevara, y las novedades que encontramos respecto al beatus ille clásico, eran conocidas con anterioridad a esa fecha. 
vara al conferir este un claro e importante valor a la parte de los negotia que no existía en el poema del literato romano. El beatus ille pone su centro de interés en la defensa del mundo del campo y sus beneficios, pero la crítica a la corte se entiende solo de manera indirecta gracias al personaje de Alfio, usurero que, a través de la ironía horaciana, sueña (aparentemente) con una vida retirada en la aldea mientras amasa sus riquezas y, al fin, piensa realmente solo en su lucro.

En Guevara, en cambio, se van a equiparar en importancia los dos elementos en relación y se va a insistir de forma explícita en esos vicios del mundo cortesano, cuyo mal, afirma este autor muy modernamente, «no está en la corte sino en los hombres que la habitan» (Márquez Villanueva 1998: 102); la consecuencia del rechazo sincero de las ambiciones propias de la corte, y solo eso, hacen recurrir a Guevara al beatus ille y al deseo de una vida en la paz del campo ${ }^{4}$. Hay ahora, por tanto, un equilibrio entre el menosprecio de la corte y la alabanza de la aldea, elementos que se formulan en esta obra como tal ya desde su título, y que entendemos como una derivación y ampliación del tópico horaciano. Redondo conecta, además, la obra de Guevara con la España del momento, con sus circunstancias socioeconómicas y, más en concreto, haciendo referencia a la relación corte-campo del Valladolid cortesano:

Derrière le schéma primitif qui situait le Menosprecio de Corte y alabanza de aldea dans toute une tradition, apparaissent de la sorte les préoccupations d'un Guevara, dont les intentions profondes sont liées à la situation èconomique et politique de la Castille des années 1536-1539. L'éloignement par rapport au motif du Beatus ille et l'évocation «réaliste» de la vie à la Cour et à la champagne sont ainsi à mettre en rapport avec l'objectif poursuivi par l'auteur, qui préconise un retour à la terre des petis gentilshommes campàgnards partis à la ville (1979a: 262).

Encontramos, pues, un ajuste del tópico a esa realidad renacentista que vive el franciscano y una reformulación que será capital para la literatura posterior, donde la crítica a los vicios de la corte, así como su irresistible atracción, será tan recurrente como la alabanza de la aldea.

Quizá podríamos pensar que lo que hacen todos los autores que cultivan este tópico, y nos detenemos ya en el siglo XVII y en Lope de Vega, objeto de nuestro estudio, es adecuarlo a su tiempo de una forma meramente tradicional y, podríamos decir, mecánica o «de pose», pero intentaremos mostrar en estas

${ }^{4}$ Estas ideas se relacionan, además, con una religiosidad y un ascetismo propios de la corriente franciscana. No va a aceptar Guevara un traslado a la aldea impostado, como tampoco entenderá el campo como una opción más de ocio para el cortesano, sino que la huida a la aldea solo tiene razón de ser, como decíamos, en aquellas personas que buscan el franco rechazo a ese mundo adulador de la corte y el acogimiento de una vida de paz y de cultivo de la filosofía. 
líneas que la razón no es únicamente esa, sino que puede haber un porqué (o varios) en la recurrencia al beatus ille en nuestro dramaturgo, puesto que «lo más importante en una "fuente" no es la "fuente" en sí, sino el hecho de que se haya elegido ir a beber de ella» (Salomon 1985: 164-165).

\section{LOPE Y EL BEATUS ILLE EN EL CICLO DE SENECTUTE}

Esta dicotomía del menosprecio de corte y alabanza de aldea fue recogida por la llamada «comedia nueva» desde sus orígenes a finales del siglo XVI. Como se ha venido señalando, la imagen de la corte como lugar de intrigas, vicio y maldad se muestra ya en San Isidro labrador de Madrid (1598) de Lope de Vega. Desde sus primeras obras, pues, el tópico tiene una gran presencia, fundamentalmente en sus comedias pastoriles y villanescas, por un lado, y en las urbanas o de capa y espada, por otro ${ }^{6}$. En ellas el verdadero protagonista es el espacio rural, la naturaleza y su identificación con el amor (de evidente influencia virgiliana y renacentista); se exaltará en estas piezas lo positivo del paisaje natural frente a lo artificial del mundo cortesano, centro de falsa ostentación y de mentiras. No obstante, señala posteriormente Escudero:

Esta rígida oposición campo/corte en las comedias del primer Lope evoluciona hacia una actitud integradora, observable en obras más tardías como El villano en su rincón, donde la figura del rey, y por tanto la corte, se convierte en el soporte de un cosmos no dramático, cuya ordenación jerárquica y social debe incluir el espacio rural (2002: 220).

Finalmente, llegamos a la etapa en la que nos centraremos y que comprende los últimos ocho años de nuestro dramaturgo (1627-1635), la época llamada «de senectute» (Rozas 1982) 7 o «post-Lope» (Profeti 1997). Este periodo fue especialmente duro, conflictivo y determinante para el Fénix de los Ingenios: desde el punto de vista personal, sufrió importantes cargas familiares, la enfermedad y muerte de su gran amor - Marta de Nevares-, el rapto de su hija Antonia Clara, la trágica muerte de su hijo Lope Félix en un naufragio... Desgracias que van unidas a serios problemas económicos y al paulatino descenso de su producción teatral en los corrales (y de la producción teatral en general en favor de la creación poética), como él mismo expresa al duque de

5 Entiéndase a partir de ahora con toda la amplitud de significado que hemos explicado.

${ }^{6}$ Véase el trabajo de Escudero (2002), en el que se ofrece un estudio de los espacios contrapuestos corte / aldea en un corpus de dieciséis comedias de Lope que van desde 1585 a 1597.

7 Etiqueta asimilada por la mayoría de los estudiosos posteriores, entre los que destacan Oleza (2004) o Pedraza (en Vega 2015b). 
Sessa en una famosa epístola ${ }^{8}$, quien, por cierto, nunca lo convirtió tampoco en su asalariado. Además, continúa viviendo preso del dolor que le produce el no ser reconocido en la corte concediéndole el puesto que él cree que le corresponde. Consta que Lope intenta ser cronista real, por tercera vez, en 1631 (Asensio 1963: 10), deseo frustrado que se convertirá en una obsesión hasta el final de sus días 9 .

Es significativo, además, que en 1634 y en el último año de su vida no dedique ninguno de sus poemas a personalidades de la realeza ni a ningún miembro del entorno palaciego. En este momento, como bien señaló Rozas en su relevante estudio, encontramos un Lope definitivamente desengañado del mundo cortesano y sin esperanzas. Sabe que su ansiada recompensa por la dedicación de toda una vida no va a llegarle nunca y va a poner fin a ese juego falso de ostentación y halagos a la realeza. De nada le sirven ya sus dedicatorias hipócritas: a un año de su muerte puede mostrarse sincero y desnudo de ataduras políticas y sociales, aunque muchas veces sea entre burlas y veras.

Reflejo de este momento de sinsabor es su última obra, La vega del Parnaso ${ }^{10}$, publicada póstumamente en 1637 y formada por una colección de veintiséis poemas y ocho comedias. Bastantes de esos textos se hacen eco - voluntario o involuntario, consciente o inconsciente - de la difícil situación que el poeta vive en esos años, que le hará dirigir su mirada al pasado para recuperar las formas y los temas más clásicos de la tradición grecolatina:

El movimiento de atracción y repulsión, de elogio y menosprecio del marco cortesano se percibe convulsivamente bajo las formas poéticas que, en busca de esa respetabilidad que perseguía su creador, se visten ropajes decididamente clásicos (églogas, elegías, canciones, odas, epístolas...) e invocan constantemente a los poetas modélicos (Horacio y Virgilio) que sí alcanzaron el favor de los poderosos (Pedraza en Vega 2015b, I, 23).

Pero no solo La vega del Parnaso es reflejo del sentimiento y del pensamiento de ese «Lope final», sino que otros varios textos, sobre todo teatrales, recrearán esos tópicos que encuentran un lugar privilegiado en el último ciclo de su vida. Y uno de los leit motiv que desarrollará en sus versos es el del

8 Epistolario, IV, 143-144.

9 No se nos olvida, en este mismo sentido, que otra de las razones de su «desasosiego» es el enfrentamiento con los dramaturgos jóvenes, los llamados por él mismo «pájaros nuevos». Véase al respecto González Cañal 2002 y Vega García-Luengos 2012. Sobre sus últimos intentos de ser alguien en la corte y las contrariedades vividas en este entorno durante el periodo que estamos estudiando, véanse, entre otros, los ya citados Asensio 1963: 7-27; Rozas 1982; Oleza 2003 y 2004 o Pedraza y Conde en Vega 2015b. Para profundizar en las diferentes estrategias literarias que utiliza el Fénix con el anhelo de convertirse en cronista real, remitimos al reciente trabajo de Gutiérrez Valencia (2019: 191-207, 242-244, 257-262).

${ }^{10}$ Editada en tres volúmenes por Pedraza y Conde (Vega 2015b). 
«menosprecio de corte y alabanza de aldea», tema que el poeta recupera desde esa admiración hacia los grandes clásicos en estrecha relación con el rechazo que la Corte le profesa.

\section{Comedias PAlatinas DE SENECTUd}

Dentro del género teatral, Lope dedica los últimos años de su vida principalmente a dos opciones dramáticas ${ }^{11}$ : las comedias de capa y espada y las comedias palatinas ${ }^{12}$. Nosotros estudiaremos algunas de las comedias del segundo grupo, en concreto aquellas que recrean, de una u otra manera, el tópico del beatus ille. Siendo más concretos, cinco de ellas: Del monte sale quien el monte quema (1627), La boba para los otros y discreta para sí (1635), La mayor virtud de un rey (1634-1635), Porfiando vence amor (1624-1630) y ¡Si no vieran las mujeres! ${ }^{13}$ (1631-1633), las tres últimas recopiladas en la citada obra póstuma del Fénix de los Ingenios.

«El universo palatino es, como ningún otro, el teatro de la fortuna del héroe y de la mudanza de su destino» (Oleza 2003: 607), mudanza que trae consigo un cambio de escenario obligado y que Lope aprovecha a la perfección para formular ese enfrentamiento del mundo de la corte con el de la aldea. En las cinco comedias que estudiaremos encontramos este cambio de espacio insertado en diferentes construcciones dramáticas: personajes que son expulsados de la corte después de sufrir acusaciones falsas, normalmente fruto de la envidia (Porfiando vence amor), personajes que son requeridos en la corte tras haber sido criados en el bucólico mundo rural, donde han vivido siempre hasta ese momento (La boba para los otros y discreta para sí y iSi no vieran las mujeres!), la combinación de ambos esquemas (Del monte sale quien el monte quema) y personajes que deciden retirarse al campo sin haber sido desterrados,

11 Véase Oleza 2003.

12 Seguimos la definición y clasificación de comedias palatinas señalada por Zugasti (2015), quien distingue las comedias palatinas cómicas (rasgo definitorio de este tipo de comedias para algunos estudiosos) de las palatinas serias (etiqueta desarrollada por Zugasti en el citado trabajo, así como en otros anteriores). Dentro del conjunto de las comedias que estudiaremos, palatina cómica se considera La boba para los otros y discreta para sí, mientras que las demás formarían parte de las serias.

${ }^{13}$ La primera de ellas ha sido editada por Porteiro Chouciño (Vega 2007), la segunda carece actualmente, que sepamos, de edición crítica (más allá de la edición digital realizada por Purificaciò Mascarell en 2015 en la Biblioteca Digital ARTELOPE); y las tres últimas forman parte, como decimos, de la reciente edición de La vega del Parnaso, en este caso bajo el cuidado de J. Cano Navarro. Oleza (2003) y Porteiro (Vega 2007) apuntan la presencia del tópico en todas las comedias, excepto en La mayor virtud de un rey, que Oleza considera drama histórico y no comedia palatina. Cano Navarro, en cambio, sí señala la presencia de esta dicotomía en su edición de la citada comedia. 
a la espera de que el rey solicite sus servicios y con el fin de vivir en paz y sin las intrigas de la corte (La mayor virtud de un rey) ${ }^{14}$.

Además de la presencia de un héroe (o heroína) que sufre los avatares del destino, es importante en este tipo de comedias el lugar en el que se enmarca la acción, que siempre ha de ser lejano, exótico (para el espectador de la época, se entiende), de ambiente extranjero. Elemento que también cumplen estas cinco obras, presentando, además, cada una de ellas, un espacio geográfico diferente dentro del mapa europeo: Del monte sale se desarrolla en Francia, La boba en Italia, La mayor virtud en Portugal, Porfiando en Hungría y Si no vieran en Alemania. El Fénix vuelca en estas piezas un tópico (el del beatus ille) que trae consigo, en general, una crítica bastante cruda al mundo áulico. Ahora bien, el poeta se atreve a censurar ese escenario palaciego de excesos, corrupción y vicios porque lo hace con cierta sutileza, enmarcándolo, como es habitual en las comedias palaciegas de los dramaturgos áureos, lejos de la corte española para velar y disimular en buena medida su denuncia.

Intentaremos analizar cómo (re)crea Lope estos dos espacios y de qué manera va cargándolos de valor; intentaremos, así mismo, relacionar dicho estudio con la función concreta que cada uno de los escenarios tiene para el desarrollo de las tramas ${ }^{15}$. Esos espacios se empapan de un significado que, en varias ocasiones, trae consigo un cambio de actitud en algunos de los personajes, no solo aparentemente, sino hasta en lo más hondo de sus actuaciones. Veremos, pues, cómo el tópico del menosprecio de corte y alabanza de aldea, de gran tradición literaria, es moldeado y adaptado por Lope en aras de sus intereses tanto dramáticos como personales. Compartimos, en este sentido, la siguiente afirmación de Rubiera:

No cabe duda de que muy a menudo el dramaturgo dota a los espacios dramáticos de valores suplementarios que permiten su interpretación simbólica, sobre todo cuando son repetidos y confrontados en varias piezas distintas, normalmente pertenecientes a un mismo género. Jardín, gruta o cueva, palacio, campo de batalla, monte o selva, mar, calle, interior doméstico... son espacios que el poeta dramático puede utilizar para proyectar metafóricamente su visión del mundo, mediante un sistema de identificaciones y de oposiciones que en el fondo le permiten, por ejemplo, tematizar cuestiones como el amor, el honor o la violencia y dialécticas tan explotadas como las de libertad/destino, mundo rural/mundo urbano, libertad/opresión, civilización/barbarie, hombre/mujer (2005: 95).

${ }^{14}$ A partir de ahora nos referiremos a ellas como Porfiando, La boba, Si no vieran, Del monte sale y La mayor virtud, respectivamente.

15 De acuerdo con Gavela (2000: 561) en su afirmación de que «cualquier conclusión debe partir de un análisis individual o genérico de la función dramática que desempeña cada elemento». 


\section{El ESPACIO DRAMÁTICO DE LA ALDEA}

El escenario rural es representado en todas estas comedias de una manera fundamentalmente tradicional, es decir, como descripción de un bucólico locus amoenus. Serán abundantes las referencias a los valles, montes, fuentes, flores, ríos, arroyos, pájaros, arboledas, bosques... En todas ellas hay al menos un parlamento en el que se hace referencia a ese lugar de paz y tranquilidad, cuyo paisaje tanto acompaña. El espacio «real», aunque indeterminado en alguna ocasión, siempre será el campo, la aldea o una quinta, con la especificación de la presencia del monte en La boba y Del monte sale.

Dice Escudero (2002: 214): «los ejemplos más numerosos de creación espacial, tanto rural como urbana, corresponden a signos figurales o referencias textuales. Y su referencia básica se establece a la hora de cuantificar los distintos espacios que refieren». Siguiendo esta idea podemos afirmar que el mundo rural aparece mucho más descrito que el de la corte, del cual tenemos información únicamente por las intrigas que allí acaecen. Además de los elementos naturales propios del locus amoenus que ya hemos señalado, percibimos un número más alto de referencias verbales al paisaje bucólico (respecto al de la corte, que aparece menos individualizado) y a todo lo positivo que conlleva: reflejo del estado de ánimo del personaje, lugar propicio para el amor y testigo de este, marco de libertad y naturalidad, etc. Pero no solo captamos estos significados a través de las referencias verbales, sino que hay un elemento fundamental, como también veremos detenidamente en algún caso, que tiene que ver con el atuendo, las diferentes vestimentas que utilizan los personajes en uno y otro escenario, y que se carga de una simbología particular.

En primer lugar, mostraremos algunos parlamentos en los que los diferentes protagonistas o personajes de las comedias describen este espacio tan idílico. En Del monte sale ${ }^{16}$, el conde Enrique es víctima de las infamias que los cortesanos envidiosos vierten sobre él para alejarlo del trono francés. Desterrado de la corte, se refugia en la aldea, donde encuentra la paz y el descanso. Cierra la segunda jornada un soliloquio en el que el noble hace una reflexión con la que exalta el mundo geórgico y todos los elementos naturales que forman su locus amoenus. Estos aparecen en contraposición del ambiente cortesano, centro de «lisonjeras lenguas»:

16 Es esta la comedia en que encontramos más referencias al tópico del menosprecio de corte y alabanza de aldea, pero nos ceñiremos únicamente a la explicación de uno o dos ejemplos en cada uno de los apartados que iremos analizando. De igual manera procederemos en el estudio de las demás comedias, puesto que sería un trabajo demasiado prolijo aportar absolutamente todos los casos de la presencia del tópico que conforman estas comedias. 


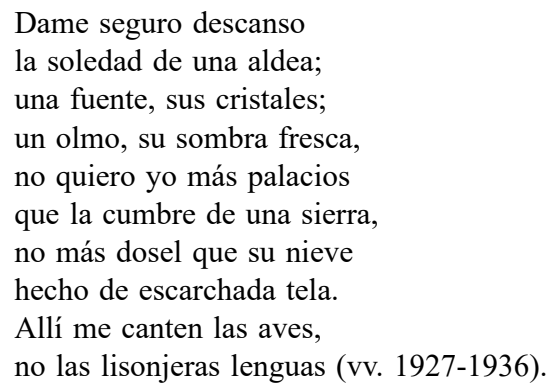

Es interesante recordar otro parlamento que, también en boca de Enrique, refleja la misma idea. Se produce al final de la segunda jornada (vv. 2085-2094) y supone el retorno del conde al campo, con una segunda desilusión, por tanto, del ambiente áulico, donde ha vivido de nuevo una serie de enfrentamientos (algunos de los cuales causados por Narcisa, protagonista femenina) que han vuelto a provocar la desconfianza del monarca.

En Porfiando asistimos a un conflicto similar al de Enrique. En este caso, Alejandro (duque en la corte húngara) acusa falsamente al privado del rey, Carlos, de conspirador porque quiere ganarse el amor de Leonarda (sobrina del rey), quien, a su vez, ama a Carlos, y porque no soporta que este sea el favorito del monarca. La envidia, una vez más, es causa de unas engañosas delaciones por las que el rey ordena el destierro de su privado. En el siguiente parlamento, el labrador Fenicio describe el lugar al que el galán llega tras ser expulsado de palacio:

Silencio tienen ya los ruiseñores, y hasta los aires callan por las ramas de estos blancos jazmines olorosos, verdes mirtos y pálidas retamas; mudos los arroyuelos sonorosos atrás la plata líquida retiran, tan tristes ya, que por cantar suspiran (vv. 808-814).

Pero no solo un hombre de aldea exalta las maravillas del paisaje natural, sino que el mismo Carlos, una vez que ha vuelto a la corte, ya al final de la comedia, recuerda con nostalgia ese ambiente rural donde vivió exiliado: «¡Ay queridas soledades, / fuentes claras, verdes selvas! / ¿Qué se han hecho aquellas horas?» (vv. 2865-2867).

Cabe señalar, además, otro pasaje en el que Lucinda, dama de la corte, cuenta a su criada cómo se enamoró de Carlos. Asociaremos, sin duda, ese lugar evocado con el locus amoenus que estamos estudiando:

Estaba la florida primavera

dando colores a la verde Flora, 
cuando salí más libre y más lozana que por abril la cándida mañana. Daba ocasión ese pequeño río - espejo de los árboles que baña; que, antes de ser cristal líquido y frío, capa de plata fue de su montañaque con otras amigas de igual brío, a quien el tiempo y lo bizarro engaña, andábamos mirando en sus riberas hacer el agua con el aire esferas. Todas por los enfaldos descubrían ricos manteos, que de rizas telas con las flores del prado competían: lirios, jazmín, azahar, rosas y espuelas (vv. 639-652).

La boba ${ }^{17}$ se construye con otro esquema dramático, como apuntábamos en líneas anteriores. Su protagonista, Diana, vive como labradora en una aldea de Italia hasta que Fabio, un gracioso de la corte, se desplaza a ese lugar para confesarle que, en realidad, es hija del recién fallecido duque de Urbino y legítima heredera del título. La joven se ve obligada a abandonar los campos en que se ha criado y llega a la corte, donde los nobles ${ }^{18}$ intentan engañarla para hacerse con el título que le pertenece. En palacio se hace pasar por «boba»y se comporta como una salvaje para que sus enemigos crean que no está preparada para ser duquesa. En un momento de la segunda jornada y tras haber sufrido varios enredos por parte de sus adversarios, Diana evoca ese espacio natural de paz y soledad del que proviene, y que, como Enrique en Del monte sale, presenta en contraste con el corrupto mundo de la corte (beatus ille):

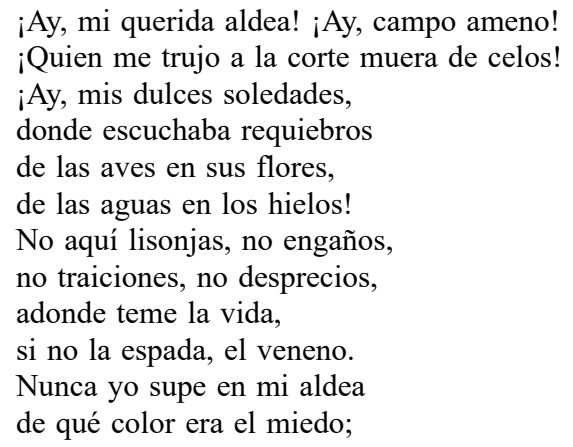

17 Es la comedia menos estudiada y de la que no nos consta que exista, como dijimos, edición crítica moderna, aunque hay una meritoria puesta en escena actual, a cargo de Lafinea teatro, dirigida por Rebeca Sanz-Conde, que ha podido verse en los Festivales de Olmedo (2014) y Almagro (2015), entre otros.

${ }^{18}$ La sobrina del fallecido duque, Teodora, y dos pretendientes que comparten la misma ambición. 
ahora, a mi sombra misma, por cualquier parte la temo.

Allá todos eran simples; aquí todos son discretos; achaque es de la mentira por ser más lo que son menos. ¡Ay, mi querida aldea! ¡Ay, campo ameno! ¡Quien me trujo a la corte muera de celos! (vv. 1760-1779).

Ese lugar que recuerda Diana, ha sido ya descrito con anterioridad por parte de Alejandro (vv. 626-645), el galán protagonista, quien quedó prendado de su belleza cuando se trasladó al monte donde vivía la joven dama al comienzo de la obra.

De La mayor virtud señalábamos que se configura de una manera peculiar, puesto que los personajes deciden abandonar la corte motu proprio, y no víctimas del destierro como sucede en las comedias anteriores. En primer lugar, Don Sancho de Mendoza (caballero), que aparece en un ambiente rural desde el inicio: siendo más concretos, en una quinta de los alrededores de Lisboa. Él mismo dice: «Dejé la corte y vine cuerdamente / a este campo a vivir, que mal pudiera / en Lisboa con honra sustentarme» (vv. 424-426). Decidió alejarse de la corte para poder criar a sus hijas, doña Leonor y doña Sol, a la espera de que el rey quiera recibir sus servicios (se ha visto, pues, como alter ego del último Lope) $)^{19}$. Y, por otro lado, el hidalgo portugués don Juan de Castro, que deja el palacio por un breve tiempo para cortejar a una de las hijas de don Sancho. Él mismo cuenta, en la primera escena, al príncipe don Juan de Portugal que, estando un día de caza por el campo, conoció a una hermosa dama, doña Sol, de quien se ha enamorado. Veamos cómo describe ese lugar que favoreció su amor y que se corresponde y se funde con la belleza de la dama:

\author{
Este Sol estaba un día \\ - cuando el otro se trasmonta \\ bañándose los cabellos \\ del mar en las crespas ondas- \\ fuera de la quinta, adonde \\ algunos álamos bordan \\ un dosel verde a una fuente, \\ que de aquel campo señora \\ también le pone a los pies \\ no menos florida alfombra, \\ en cuyas franjas de lirios \\ el agua ensartaba aljófar. \\ Mirábase en el cristal
}

19 Véase la introducción a la edición de Cano Navarro (Vega 2015c: 403) y Gutiérrez Valencia 2019: 472. 


$$
\begin{aligned}
& \text { y, trocándose las formas, } \\
& \text { el agua le daba perlas } \\
& \text { por que ella le diese rosas (vv. 159-174). }
\end{aligned}
$$

Es reseñable igualmente la descripción de la otra cara del paisaje rural que presenta esta comedia. En este caso, un lugar idílico particular, puesto que se refiere al entorno exterior de la quinta que da al mar, donde se mezcla lo maravilloso con lo tempestuoso, pues bien sabemos que el mar puede ser tan admirable como destructivo ${ }^{20}$ :

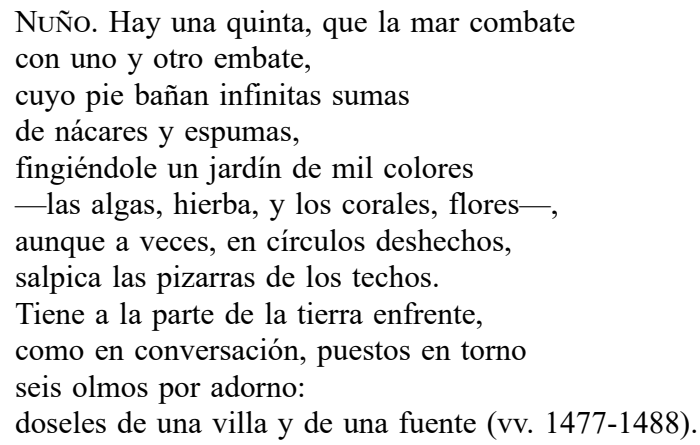

Por último, haremos una referencia a ese locus amoenus que dibuja el ambiente rural de Si no vieran. En esta comedia, como en la anterior, el tópico no es el eje central de la trama, sino que lo es el amor. Ahora bien, los espacios, como ya hemos visto, se cargan del mismo significado. Su esquema dramático es semejante al que presentan Del monte sale y La boba, aunque en este caso la protagonista, Isabela, sabe que es noble desde el principio, y es su padre, el duque Otavio, quien había sido desterrado tiempo antes del inicio de la acción (se insinúa que también por envidia, acusado de apoyar al bando enemigo del emperador) y quien la mantiene allí alejada del ruido de la corte, semejanza que comparte con La mayor virtud. El campo es descrito, como hiciera don Juan en la pieza anteriormente citada y Lucinda en Porfiando, en relación directa con la belleza del ser amado mientras se entrelaza con los tópicos elementos naturales. En Si no vieran es el caballero Alejandro quien sufre el hechizo que las cristalinas aguas del idílico lugar provocan:

Vila una tarde que bajaba al río con Flora, su parienta o su criada. Sentose en la esmaltada

${ }^{20}$ Cano percibe en esta descripción una relación directa con el momento vital de Lope y la destrucción de su querido jardín (véase la nota al verso 1484 de la edición, p. 474), al que —no hemos de olvidar- dedica un poema, «Huerto deshecho», en La vega del Parnaso. 


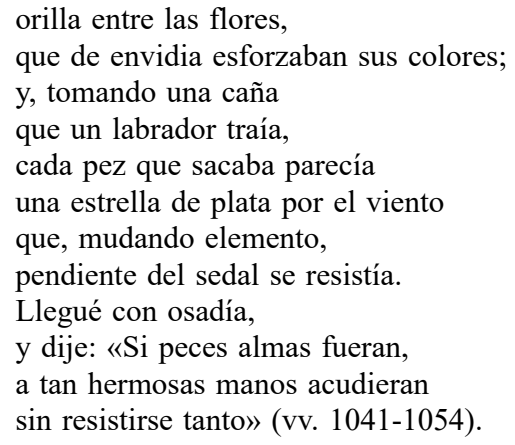

Otra de las funciones que tiene el locus amoenus es la de servir de marco ideal para que germine el amor entre los protagonistas de la comedia, como apuntábamos. La naturaleza será testigo de la relación que surge entre los amantes y reflejará, en algunas ocasiones, su estado de ánimo. En cuatro de las piezas que estamos estudiando (en todas excepto en La boba, pues la mayor parte de la acción de esta se desarrolla en palacio) encontramos versos que hacen referencia a ello. En la primera jornada de Del monte sale asistimos a varias escenas en las que Carlos y Narcisa, la pareja protagonista, se apoyan en los elementos más tópicos de la naturaleza para el surgimiento de su amor. El lirismo de los versos (véanse, por ejemplo, los vv. 10-36) crea un ambiente de armonía y felicidad que propicia esa identificación del amor con el paisaje natural.

En cambio, el tono será totalmente diferente cuando Narcisa describa el primer encuentro que tuvo con el conde, relato que hace una vez que él ya ha regresado a la corte:

Transformaba sus lágrimas la aurora
con el calor del sol por las orillas
de un manso arroyo, cuya margen dora
en pimpollos de infantes florecillas;
cuando a su gente, entonces vencedora,
que se alojaba por diversas villas,
alzo los ojos con disculpa y miro
la hermosa causa por quien hoy suspiro (vv. 1345-52).

Hemos de tener en cuenta que Narcisa, al final de la primera jornada, se desplaza a la corte y allí comprueba que su amado Enrique ha olvidado el amor que le tenía debido a la aparición de una dama, Celia, de su mismo estatus social. La joven acude a la naturaleza para rememorar el momento vivido con el conde, que tanto daño le causa en esos instantes en que su amor no es correspondido. Cabe decir que, como ejemplo de esta desolación que vive Narcisa y, por ende, de adecuación entre su estado de ánimo y el medio rural, encontramos otro fragmento de la comedia (anterior en el tiempo dramático) en el que ya buscaba esa respuesta en la naturaleza (vv. 1114-1117). 
La segunda jornada de Porfiando empieza y termina de la misma forma (como bien señala Cano en Vega 2015d: 279): Carlos expresa sus sentimientos ante la naturaleza para hacerla partícipe de ellos. Es decir, el entorno natural aparece de nuevo como testigo de los acontecimientos, muy del gusto también de la poesía renacentista. Veamos el comienzo del primer fragmento:

Desiertas soledades, riberas apacibles

- a quien la vida desterrado ofrezco-

pobladas de verdades, supuesto que insufribles

a quien padece, como yo padezco,

¿por qué culpa merezco

del rey, que me ha criado,

la ausencia y la desgracia,

que, en vida de su gracia,

me tiene en tanto olvido sepultado?

¡Oh qué tristes memorias,

presentes penas y pasadas glorias! (vv. 1035-1045).

Abandonado ese espíritu animoso por las circunstancias vividas posteriormente (como le ocurre también a Narcisa en Del monte sale), la dama Lucinda protagoniza otro extenso parlamento (vv. 2053-2104) en el que, ya avanzada la trama, cuenta sus desdichas utilizando el paisaje bucólico como espejo de su sentir. La joven, fiel enamorada de Carlos, le acompaña a la aldea cuando este es expulsado de la corte, aunque ella es consciente de que el noble ama a otra mujer, Leonarda. En el fragmento que presentamos a continuación Lucinda está sola, en el campo, y su único interlocutor es la naturaleza, que escuchará los lamentos que la dama expresa al saber que su amado se ha quedado en palacio, posiblemente aceptando los requiebros de la oportunista Leonarda:

Oíd cuánta mudanza

un firme amor, por no mudarse, alcanza:

Carlos, enternecido

de mis obligaciones

-que nunca el premio a las verdades tarda-,

ha puesto en justo olvido

las necias sinrazones,

celos y ingratitudes de Leonarda:

ya me sigue o me aguarda.

¡Oh selvas amorosas,

creced el verde manto!

$¡$ Oh fuentes, si a mi llanto

bajastes de estas peñas presurosas,

agora con más prisa

tropezaréis en vuestra misma risa! (vv. 2064-2078). 
La mayor virtud refleja del mismo modo el motivo que estamos estudiando. El lugar propicio para el amor ha sido, nuevamente, el campo, y así se lo reitera en el siguiente fragmento Don Juan a su amada, cuando ésta duda de que la ame. Ese espacio de ensueño es el testigo y será el aval de que su amor permanecerá para siempre.

Don JUAN. ¿Qué os hace dificultad que para quererme importe?

Sol. El no saber si en la corte tenéis otra voluntad.

Don JuAn. De la fuente os acordad, donde con agua de olvido ansí bañáis mi sentido, que se me hubiera olvidado si ha sido lo que ha pasado o pasado lo que ha sido (vv. 747-756).

Y, por último, veamos un ejemplo de Si no vieran. Como buena comedia barroca, presenta un enredo amoroso entre varios personajes: Otón, el joven emperador; Alejandro, quien describe el locus amoenus mientras ve a su amada en el campo, como hemos visto, y quien declama «Que el tiempo que estuvimos en la aldea, / me dio ocasión de amarla su hermosura» (vv. 1036-1037); Isabela, la bella dama; y Federico, el galán protagonista. Es él precisamente quien da voz a los siguientes versos, en que transmite su estado de ánimo en perfecta comunión con la naturaleza:

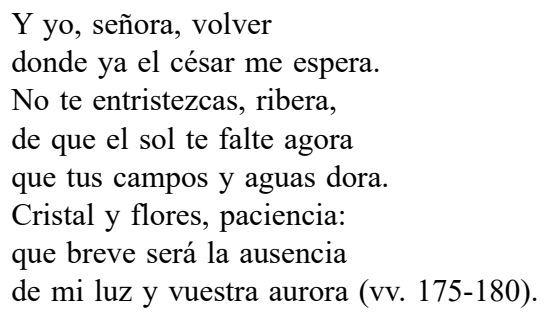

En suma, excepto en el matiz que percibíamos en la descripción de la quinta de La mayor virtud cuando hacíamos referencia a su contacto con el mar, el espacio rural ha sido siempre presentado como un lugar casi paradisiaco, favorable para el disfrute de la tranquilidad y la paz, para el surgimiento del amor e incluso como el mejor espacio para las disertaciones o lamentos amorosos de sus protagonistas. Es decir, siempre se muestra desde un punto de vista positivo, como merecido heredero de la tradición del tópico a lo largo de la historia de la literatura. No obstante, hay un pasaje en Si no vieran que supone un contrapunto a esta visión: Isabela, protagonista femenina de la comedia, con una pincelada de gran modernidad, habla de la aldea no como un lugar 
maravilloso e idílico, sino con el sentimiento de estar allí encerrada y privada sobre todo del amor, apartada de la sociedad en un espacio aburrido e inactivo:

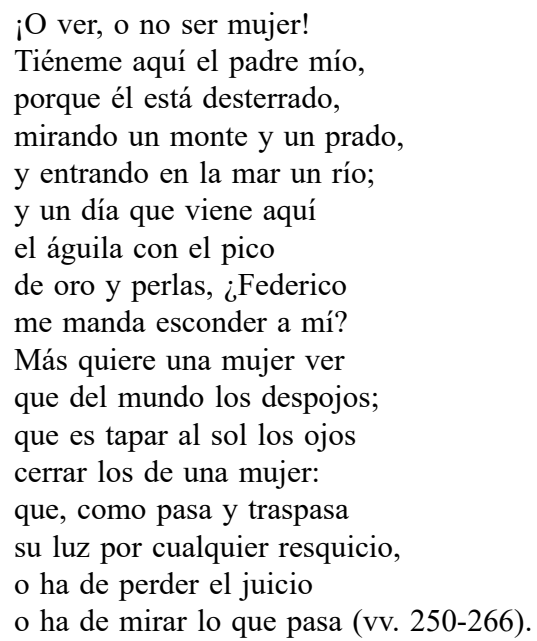

En relación directa con esto, surge el tema de la libertad. Decíamos al principio que algunos personajes muestran actitudes diferentes dependiendo del espacio en el que se encuentran, resultando más convincente y natural su actuación en la aldea. La corte los envuelve con sus malas artes y consigue que se desdigan de lo prometido a sus amadas en el campo, cegados por el poder otorgado, o incluso que se muestren agresivos con sus contrincantes, como es el caso de Enrique en Del monte sale. Es posible que el ambiente cortesano marque a cada uno de sus personajes cómo se ha de comportar, sin dejar lugar para su sinceridad, naturalidad o libertad.

Pero son, sin duda, las mujeres de estas comedias (Narcisa, Diana, Lucinda, Isabela...) quienes tienen una psicología más fuerte, desarrollada y sólida. De acuerdo con ese espíritu «moderno» y «rompedor» que las caracteriza, consiguen todo lo que se proponen y son urdidoras de muchos de los enredos que se suceden, de los que salen victoriosas. Merecerían todas ellas un capítulo especial, pero dedicaré únicamente unas palabras a Diana, la protagonista de La boba, heredera, según Navarro Durán (1997) de la Finea de La dama boba lopiana. Es este un personaje muy potente, que se muestra tal cual es tanto en la aldea como en la corte, donde, según se ha demostrado, es más difícil no tambalearse y mantenerse íntegro. Con sus astutas armas engaña a sus engañadores y se corona finalmente como la duquesa de Urbino, pues, como indica la citada estudiosa (1997: 59), no solo «se sabe inteligente», sino que «lo demuestra». ¿Quizá la clave esté en haberse criado en la aldea, lejos de ese ambiente pérfido? Sea como fuere, lleva su paz y su justicia a la corte, donde también se ha ganado su libertad. 


\section{El ESPACIO DRAMÁTICO DE LA CORTE}

El escenario áulico, como señalábamos, aparece menos descrito que el mundo rural. No conocemos las características físicas que lo componen (aunque todos imaginemos un urbano «anti-locus amoenus») $)^{21}$, pero sí somos conscientes de las acciones que allí discurren y participamos del comportamiento que muchos nobles observan para con los otros. En estas comedias acontecen intentos de asesinato, homicidios consumados, falsas acusaciones, intrigas planeadas, traiciones..., cuya causa fundamental es la envidia, uno de los temas predilectos de Lope de $\mathrm{Vega}^{22}$. La consecuencia, por otro lado, será el cambio del destino, otro de los motivos importantes de la época y necesario en los dramas palatinos: la mudanza y la fortuna. De ahí que, en nuestras piezas, muchos de los personajes se desplacen de la corte a la aldea y de esta a palacio, que pasen del favor real al destierro y de esa expulsión al perdón y la recuperación de su nobleza. La fortuna, que gira como una rueda, los mueve a su antojo en un vaivén que los lleva de un polo al otro y que rompe, evidentemente, con la famosa unidad de lugar que Lope ya desechaba en su Arte nuevo de hacer comedias.

De una manera más concreta, en Del monte sale se suceden dos asesinatos, el del Príncipe heredero y el del Gobernador. El conde Enrique es acusado de cómplice y, como sabemos, desterrado de la corte. Por su parte, el privado Carlos, en Porfiando, sufre las falsas acusaciones que causan su exilio y, una vez que ha vuelto a palacio, intentan matarlo. Diana, protagonista de La boba, se alía desde el principio con Fabio, quien, por un lado, advierte a la joven de los peligros que se encontrará en la corte, pero, por otro, conspira (aunque en la sombra) contra el poder actual de la mano de los Médicis de Florencia, que terminarán, por medio del casamiento entre Diana y Alejandro, hermano del duque florentino, alcanzando también el deseado poder junto con los Urbino. En La mayor virtud y en Si no vieran la corte no es un hervidero de corrupción como en las comedias anteriormente estudiadas, sino que se muestra únicamente como un lugar de enredos amorosos y celos, como es habitual en todas las comedias barrocas. Ahora bien, hemos de recordar que en Si no vieran Belar$\mathrm{do}^{23}$ apunta que su señor, el duque Otavio, vive desterrado de la corte fruto también de las envidias de los cortesanos que lo rodeaban.

${ }^{21}$ Además, su descripción quizá sería redundante para los espectadores, quienes, en general, conocían ese espacio a la perfección.

22 Véase Cano 2003, donde estudia la figura del valido en las comedias de La vega del Parnaso y, por ende, analiza los temas de la envidia y la mudanza.

${ }^{23}$ En este personaje es evidente la autorreferencia de Lope de Vega, quien utiliza en varios de sus textos ese nombre para hablar de sí mismo. Véase el exhaustivo estudio de Gutiérrez Valencia (2019: 268-269, 330, 343-370, 445-457). 
Son varios los personajes que se hacen eco de este tema, íntimamente unido a la ambición y el egoísmo. Para algunos aristócratas, como comprobaremos a través de su comportamiento y como ya se ha indicado en el análisis anterior, todo vale si el fin es alcanzar el poder real ${ }^{24}$. Además de en esta época de senectud que estamos estudiando, no hemos de olvidar que el mismo Lope había intentado ser cronista real de Felipe III ya en 1611, y nuevamente en 1620, y que utilizó sus obras y su éxito literario en muchas ocasiones como elemento adulador para conseguir su deseo de medrar en la corte ${ }^{25}$, obsesión que, como ya se ha dicho, lo acompañará hasta el final de sus días. Sus personajes, con mayor crudeza, lucharán de otra manera y sin escrúpulos por alcanzar igualmente el poder.

Centrándonos de nuevo en las comedias, ya sabemos que el conde Enrique, en Del monte sale, es traicionado doblemente. La segunda de las veces, conseguido de nuevo el favor real, le suscita mayor perplejidad, pero su perspicaz criado, Feliciano, le dará una respuesta en la que achacará el mal que está sufriendo a la envidia que todos le tienen (aunque se le escapan las mentiras que la celosa Narcisa ha planeado para que vuelva con él): «No es posible que esto sea / sino envidia de traidores» (vv. 1836-1837).

Pocos versos más adelante, Enrique expresa, en un monólogo, lo que significa para él el espacio áulico. Presenta todos los rasgos negativos que hemos señalado:

\author{
$¡ O h$, fortuna de las cortes! \\ $¡ O h$, mar de infames sirenas! \\ $¡ O h$, peligro deseado, \\ posta que la vida llevas! \\ ¡Oh, piélago de mentiras! \\ $¡ O h$, vil quimera compuesta \\ de lisonja y ambición, \\ murmuración y soberbia,
}

${ }^{24}$ Aunque no podemos detenernos en ello, hemos de tener en cuenta aquí la importancia que las ideas maquiavélicas y tacitistas tuvieron en la época y, de una forma más o menos directa, se refleja en la actuación de algunos personajes nobles que encontramos en estas piezas.

${ }^{25}$ Véase el estudio de Wright (2001) para profundizar en estas estrategias que utiliza Lope en el reinado de Felipe III a través de varias de sus obras épicas (Dragontea, La Jerusalén conquistada), novelescas (El peregrino en su patria), pastoriles (Arcadia), hagiográficas (Isidro) o teatrales (La hermosa Ester, El premio de la hermosura, Los ramilletes de Madrid); ya sea mediante las dedicatorias al rey, a su valido o a diferentes nobles, como organizando espectáculos teatrales para ellos, tratará en vano de alcanzar un puesto privilegiado en la corte. Asimismo, son interesantes las reflexiones de Sánchez Jiménez (2006: 72-79) en torno a los intentos fallidos que Lope continúa protagonizando al pretender nuevamente ganarse el favor real (con la publicación de la Circe, por ejemplo), en este caso ya con Felipe IV en el trono. 
donde el mentiroso vulgo

ni aun la majestad respeta! (vv. 1907-1916).

En Porfiando es Carlos quien experimenta la desilusión del ambiente palaciego, aunque lo haga en un tono distendido y feliz por el lugar en el que se encuentra. En contraposición con la aldea - ese ámbito de la «verdad» donde Carlos se cree el mismo rey-, la corte es también calificada como el lugar de la desigualdad y la envidia (véanse los versos 2173-2188).

En el fragmento que hemos mostrado anteriormente de La boba para describir el medio rural, Diana ya nos anticipaba su opinión sobre la corte, a la que tildaba de ser un espacio de «lisonjas», «traiciones», «engaños», «desprecios» y «mentiras». Además de todos estos vicios y pecados, no falta el más reiterado: la envidia; aunque esta vez en palabras de Alejandro, galán de la comedia:

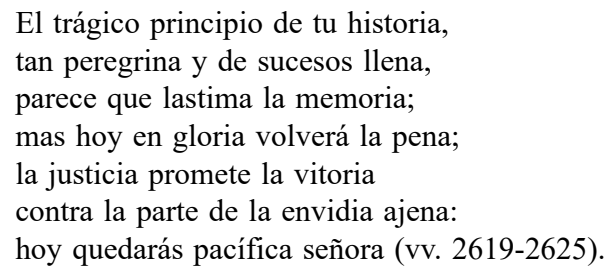

Llegados ya al desenlace de la trama, el noble puede decir victorioso que Diana ha conseguido vencer a todos aquellos que la envidiaban y que querían quitarle su lugar en palacio, pero el camino no ha sido en absoluto fácil.

El gracioso de La mayor virtud, Mendo, llega a la corte con una carta que doña Sol le ha escrito a Don Juan. Cuando se va acercando al lugar comparte su reflexión, donde no faltará el tópico de la falsedad cortesana:

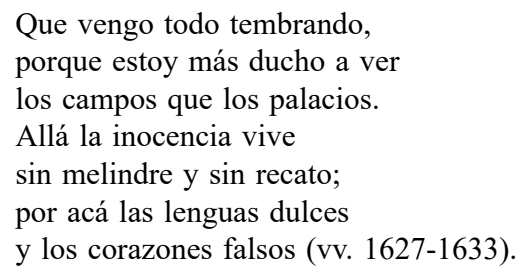

Sentenciosa es también la opinión de Don Juan, que al final de la comedia exclama: « $i$ Oh envidia, bien te llamaron / hija de la corte!» (vv. 2596-2597).

Llama la atención lo asumido que tienen los personajes que la envidia es la causante de todos los males y la reina del ambiente palaciego. Aunque el caballero Federico, en Si no vieran, se jacta de no haber sido nunca preso de ella: «Como nunca, Alejandro, me ha tocado / la envidia de la corte, / siempre camino por distinto norte» (vv. 1021-1023). 
Señalábamos unas líneas más arriba que en $S i$ no vieran no se presenta una corte tan cruda como en otras comedias que estamos estudiando, pero lo cierto es que los enredos que allí sobrevienen, aunque sean meramente amorosos, consiguen quitar la paz a quienes a ella acuden. Es el caso del duque Otavio, padre de Isabela, que se desplaza a palacio para poder casar a su hija, hecho que vive con desasosiego:

OTAvio. Inquieto,

suspenso, triste y cobarde

me tiene la dilación

del tratado casamiento.

Ya, Belardo, me arrepiento,

y no con poca razón,

de haber venido a la corte.

Belardo. Bien estabas en tu aldea.

Otavio. Quien esta inquietud desea, su vida en la corte acorte (vv. 2184-2193).

Belardo, villano, es el guardadamas de Otavio, y, como su señor, es feliz en la aldea. Tampoco pierde la ocasión de expresar en un aparte lo que se temía de la corte:

Bien me dijeron allá:

«¿A la corte vais, Belardo?

Los cortesanos harán

rica la pobreza vuestra».

Ya son relojes de muestra:

que señalan y no dan (vv. 2616-2621).

Asimismo, una de las afirmaciones que venimos sosteniendo en estas líneas es la actitud cambiante que muestran los protagonistas de, sobre todo, Del monte sale, de acuerdo con la mudanza que experimentan. Veamos, pues, cómo se desarrolla en el discurrir de sus propios versos.

El conde Enrique alberga sentimientos contradictorios así se encuentre en la aldea, lugar de paz y surgimiento del amor hacia Narcisa, o en la corte, donde es víctima de todas las intrigas y traiciones que allí suceden, así como de la atracción que por Celia siente. El traslado a palacio será determinante para la actitud del conde y él mismo se convencerá de que debe olvidar lo que en el campo pasó con Narcisa porque su diferente condición social les hace irreconciliables. El galán pedirá a su amada labradora que vuelva a la aldea y que olvide lo que entre ellos ha sucedido (vv. 902-909).

El mismo criado del noble, Feliciano, se percata de lo que conlleva el cambio de escenario: « $¡ O$ Oh, Juana mía, / todo se olvida en la corte! / En su mar andamos ya» (vv. 1061-1063).

Narcisa, mujer de armas tomar, jura vengarse de esta afrenta y volverá a palacio para injuriar al conde con sus mentiras ante el rey. Esta vez, no solo 
fruto de la envidia, sino también de los celos, otro de los temas predilectos de la comedia barroca. La imparable labradora se hará pasar primero por Doña Sol, una dama leonesa que denuncia a su supuesto marido, Enrique, por haberla abandonado con sus tres hijos; y después se convertirá en Madama Flor, quien denuncia nuevamente al conde, en este caso por haber supuestamente violado a su inventada hermana Lucrecia. Estas graves acusaciones, que podrían incluso poner en peligro la vida de Enrique, le sirven a la joven dama para lograr su cometido: que el conde vuelva a la aldea, donde todas esas artimañas no son necesarias.

En definitiva, como hemos podido ver a lo largo de este análisis, Lope de Vega crea estas cinco comedias con el fin, más o menos explícito, de contraponer los dos mundos dicotómicos por excelencia: la corte y la aldea. Ambos espacios se han ido construyendo a través de las referencias verbales de los personajes y de los acontecimientos que allí han ido ocurriendo: la corte, como el lugar de los vicios; el campo, como un locus amoenus, escenario de virtudes. El consecuente beatus ille, además, ha sido complementado por el tema más universal de todos: el amor. En la aldea se ha mostrado puro, natural, sin ataduras sociales, y se ha asemejado a las maravillas de la naturaleza, que, en muchos de los casos, ha sido también su testigo. En palacio, en cambio, el amor se presenta interesado y destruido por la envidia, la corrupción y la ambición de los cortesanos.

Es llamativo, en cambio, el indefectible retorno a la corte. Aunque los personajes confiesan que la aldea es el lugar de la felicidad, ninguno de ellos termina la comedia viviendo en el campo, sino que, al ser reclamados nuevamente en palacio, vuelven a él. Quizá es Carlos, nuestro protagonista de Porfiando, quien siente más sinceramente el abandono del medio rural, como podemos percibir cuando declama estas palabras:

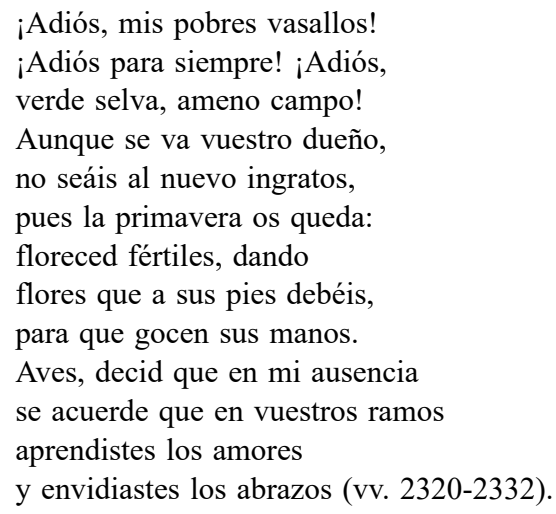

Pero aun Carlos, que en la corte seguirá acordándose de la aldea, como hemos visto en otro parlamento, se ve obligado a abandonar ese espacio de 
paz. Intentaremos concluir al final de estas líneas con una hipótesis que explique por qué, en Lope de Vega, la crítica al mundo palaciego no se corresponde con la actuación final de sus personajes y, por tanto, con el desenlace de sus tramas.

\section{EL ATUENDO DE LOS PERSONAJES EN LA CREACIÓN DE LOS ESPACIOS}

Todo estudioso de teatro clásico es consciente de cómo se construyen los espacios en la comedia nueva, sobre todo desde la aparición del esclarecedor trabajo de Rubiera (2005). En él se nos explica que, por un lado, los espacios se asocian a las situaciones dramáticas que en ellos se desarrollan reiteradamente, con su consiguiente identificación entre el espacio en concreto con el valor simbólico que el poeta quiera darle (piénsese, sin ir más lejos, en la recreación del beatus ille que estamos estudiando); $\mathrm{y}$, por otro lado, la construcción espacial a través de procedimientos escenográficos que también se van haciendo fácilmente identificables.

Además de estas dos opciones (e incluso dentro de ellas) y de las múltiples referencias verbales que nos indican en qué espacio nos encontramos, el teatro juega con un recurso fértil y determinante: el vestuario ${ }^{26}$.

En el espectáculo siempre hay un espacio escenográfico no verbal creado por el vestuario del actor, que, más neutro o más significativo, es obligatorio en la presentación del personaje. Proporciona informaciones muy diferentes sobre su edad, su condición social, su oficio o sobre el lugar y el momento de la acción, por lo que puede ser un elemento clave para una rápida caracterización (Rubiera 2005: 90).

En las comedias que estamos analizando el vestuario desempeña un papel fundamental porque, en la mayoría de ellas, se utiliza como un recurso determinante para el enredo que se desarrolla en escena. Como es natural, los nobles que son desterrados a la aldea han de integrarse en el nuevo ambiente, y sus ropas deben indicárselo al espectador. Ocurre igualmente con las protagonistas que se han criado en el campo, pero que, en realidad, pertenecen a un estamento social elevado: lo primero que tienen que cambiar es su vestuario para llegar a palacio con decoro. Dependiendo, por tanto, del atuendo que lleven los personajes en escena sabremos en qué espacio se encuentran (dato que, para el lector, viene marcado en las acotaciones).

${ }^{26}$ Imprescindible es también, en este sentido, el volumen que Ruano de la Haza (2000) escribió sobre la puesta en escena en el teatro áureo. Véase en concreto el capítulo dedicado al vestuario teatral: 73-100. Sobre este elemento capital del mundo de las tablas, se recomienda igualmente el volumen que el Cuaderno de Teatro Clásico le dedicó en el año $2000 \mathrm{y}$, con especial interés, el «Glosario» que se incluye en el mismo bajo la autoría de Madroñal (2000: 236-301). 
Lucinda, nuestra protagonista de Porfiando, aparece prácticamente en toda la comedia vestida de labradora, mimetizada con el entorno campestre en el que se mueve. Pero no solo su vestimenta será «de bizarra» en la aldea, donde ha conseguido, finalmente, enamorar a Carlos, sino que en el momento en que el conde ha recuperado su lugar en la corte y Lucinda llega a palacio, lo hace también vestida de labradora. Leonarda, su eterna adversaria, no la reconoce: «¿Tanto tiene que hablar, Celia, / esta villana con Carlos?» (vv. 2894-2895), pero su amado sí. De una manera simbólica, el conde elige a su dama con el disfraz de villana.

Como hemos señalado, muchas veces el atavío sirve para despistar a algunos personajes, que se hacen irreconocibles los unos a los otros fuera de su espacio original. Un ejemplo muy significativo es el que nos muestra Lope en Si no vieran. Belardo, villano, el guardadamas del duque Otavio, está en la corte junto a Isabela, la dama protagonista. En el siguiente fragmento veremos cómo parodia la forma en que ha debido vestirse, con un atuendo con el que el emperador no lo reconoce:

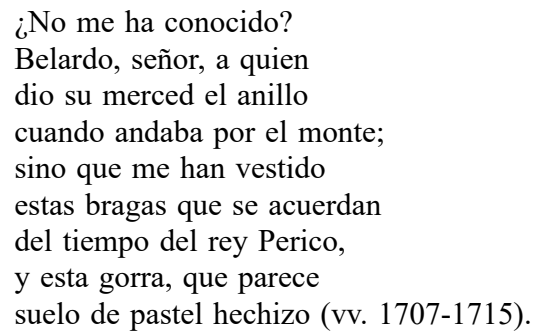

Lo mismo le ocurre a Mendo (La mayor virtud), que se acerca a la corte vestido «de camino» y Don Juan no consigue identificarlo:

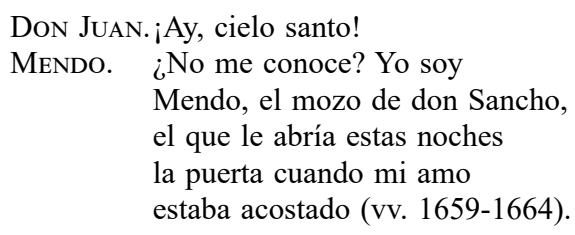

Vemos, pues, cómo esta contraposición entre la corte y la aldea no se percibe únicamente a través de los parlamentos, de la actuación de los diferentes personajes y de la simbología que hemos ido analizando, sino que el vestuario es un elemento capital para la formación de estos dos espacios y para la creación de este choque entre un mundo y el otro. 


\section{REFLEXIÓN FINAL}

Es una realidad que Lope de Vega vivió los últimos años de su vida obsesionado por alcanzar un lugar en el entorno cortesano, deseo que lo acompañó, como se ha dicho, a lo largo de toda su existencia. Y creemos que es también bastante evidente que esta preocupación la volcó en su literatura, como hizo con muchas de sus vivencias a lo largo de toda su carrera. Ahora bien, no es tan fácil discernir qué pensaba verdaderamente el poeta acerca del tópico que hemos estudiado en estas comedias y en cuál de los dos polos se situaba en su vida: ¿es sincera esa exaltación tan reiterada del mundo de la aldea? ¿Lope habría querido trasladarse al campo para vivir lejos del ruido de la corte? ¿Qué le obligaba realmente a permanecer en la ciudad? ¿O es solo este menosprecio fruto de la vigencia de un tópico de larga tradición literaria?

A nuestro modo de ver, Lope de Vega vivió sumido en una eterna contradicción en cuanto a la corte y la aldea se refiere. Cierto es que algunas de sus poesías, incluso su epistolario, dan fe de la necesidad que tenía Lope de respirar otro aire que el palaciego; en ellas el Fénix expresa un verdadero y personal desengaño de la corte, como muchos otros contemporáneos (Salomon 1985: 296-297). Pero, por otro lado y de forma totalmente contraria, nos consta que los nobles que eran expulsados de su dominio vivían con angustia esa situación de destierro, a la espera de que el rey los perdonara para volver al centro de poder, hecho que hace pensar a Ferrer que esa expresión del beatus ille en la literatura «se trata de un sofisticado juego» (1999: 7).

Sería incongruente afirmar que el poeta, que tanto luchó por ser alguien en palacio, deseara vivamente un destierro en el campo. En cambio, quizá sí tiene más sentido a través de la afirmación que hace Antonio de Guevara en su Menosprecio de corte y alabanza de aldea: «y esto no lo hazía yo de virtuoso, sino de muy desesperado, porque el Rey no me dava lo que yo quería y el privado me negava la puerta» (Márquez Villanueva 1999: 136). Es posible que Lope despechado (recordemos todos los desaires que sufrió por parte de los poderosos, $\mathrm{y}$, en especial, el desplazamiento definitivo que en estos últimos momentos de su vida experimenta con la aparición de los «pájaros nuevos» en el contexto áulico), quisiera mostrar las miserias de la corte y así, además, poder reflejar sus más sinceros anhelos de un hombre de ciudad al que le habría gustado disfrutar del favor real para poder retirarse al final de su vida, por decisión propia, a la paz del mundo rural, como hicieron sus grandes referentes latinos: Virgilio en ciertos momentos de su vida y, sobre todo, Horacio.

Se explicaría, por tanto, ese eterno retorno a la corte (pues todos los personajes, aun después de expresar su desprecio al ambiente palaciego, vuelven a él) no solo como una estrategia dramática que pide el restableci- 
miento del orden inicial, sino como el hálito de esperanza del Fénix, quien proyecta en la literatura el gran sueño que nunca pudo cumplir en vida. La aldea sería para él ese lugar en el que poder sentirse un noble querido, desterrado pero recuperado nuevamente por los poderosos, o de una forma más verosímil y como ya se ha estudiado, el Otavio de La mayor virtud de un rey, que se retira voluntariamente al campo, o el Belardo de iSi no vieran las mujeres!, quien solo en el entorno bucólico se muestra feliz, sin ataduras y descansado.

Sea esta hipótesis más o menos cierta, lo indiscutible es que el gran Lope llega a la época de senectud con una maestría verdaderamente admirable. Fruto de ello son al menos estas cinco comedias, creadas con un verso ágil y envolvente que van dibujando unas tramas semejantes entre sí, como hemos estudiado, y que repiten una y otra vez esa obsesión que supone para el poeta el tópico del beatus ille. El Fénix de los Ingenios, en su incansable anhelo por ser y por permanecer, deja por escrito ese deseo de eternidad en boca de su alter ego Belardo:

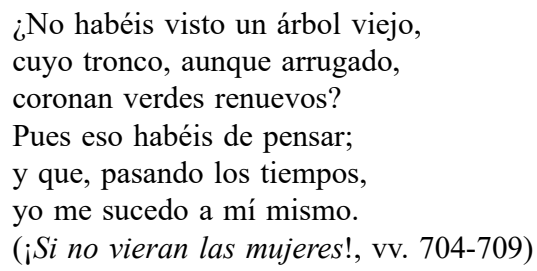

\section{FUENTES}

Vega, Lope de (1935-1943). Epistolario de Lope de Vega Carpio, ed. Agustín González de Amezúa. Madrid: RAE, 4 vols.

Vega, Lope de (2007). Del monte sale quien el monte quema, ed. Ana $\mathrm{M}^{\mathrm{a}}$ Porteiro Chouciño. Santiago de Compostela: Universidade, Servizo de Publicacións e Intercambio Científico.

Vega, Lope de (2015a). La boba para los otros y discreta para sí, ed. Purificació Mascarell. Valencia: Biblioteca Digital ARTELOPE.

Vega, Lope de (2015b). La vega del Parnaso, ed. Felipe B. Pedraza Jiménez y Pedro Conde Parrado. Ciudad Real: Instituto Almagro de teatro clásico, 3 vols.

Vega, Lope de (2015c). La mayor virtud de un rey, ed. José Cano Navarro en Felipe B. Pedraza Jiménez y Pedro Conde Parrado (eds.), La vega del Parnaso, I. Ciudad Real: Instituto Almagro de teatro clásico, pp. 391-535.

Vega, Lope de (2015d). Porfiando vence amor, ed. José Cano Navarro, en Felipe B. Pedraza Jiménez y Pedro Conde Parrado (eds.), La vega del Parnaso, II. Ciudad Real: Instituto Almagro de teatro clásico, pp. 195-316.

Vega, Lope de (2015e). ¡Si no vieran las mujeres!, ed. José Cano Navarro, en Felipe B. Pedraza Jiménez y Pedro Conde Parrado (eds.), La vega del Parnaso, III. Ciudad Real: Instituto Almagro de teatro clásico, pp. 599-749. 


\section{BIBLIOGRAFÍA CITADA}

Alciato, Andrea (2003). Los emblemas de Alciato. Traducidos en rimas españolas. Añadidos de figuras y de nuevos emblemas en la tercera parte de la obra (facsímil), ed. Rafael Zafra. Palma de Mallorca: Juan J. Olañeta Editor - Universitat de les Illes Balears.

Asensio, Eugenio (1963). «Ensayo de interpretación, estudio preliminar al facsímil de Lope de Vega», en Huerto deshecho. Madrid: Castalia, pp. 7-23.

Cano Navarro, José (2003). «La figura del valido en las comedias palatinas de La vega del Parnaso», en Santiago Talavera Cuesta e Ignacio Javier García Pinilla (coords.), Charisterion, Francisco Martín García oblatum. Cuenca: Universidad de Castilla-La Mancha, pp. 467-486.

Escudero, Juan Manuel (2002). «Espacio rural versus espacio urbano en las primeras comedias de Lope de Vega», en Homenaje a Frederic Serralta: El espacio y sus representaciones en el teatro español del Siglo de Oro. Actas del VII coloquio de GESTE (Toulouse, 1-3 de abril de 1998). Madrid: Iberoamericana - Vervuert, pp. 209-229.

Ferrer Valls, Teresa (1999). «Bucolismo y teatralidad cortesana bajo el reinado de Felipe II», Voz y letra. Revista de Filología. X, 2, pp. 3-18.

Gavela García, Delia (2000). «La función dramática de la corte en algunas comedias de Lope de Vega», en Florencio Sevilla y Carlos Alvar (eds.), Actas XIII Congreso AIH. Madrid: Castalia, vol. I, pp. 554-564.

González Cañal, Rafael (2002). «Lope, la corte y los "pájaros nuevos”», Anuario Lope de Vega. 8, pp. 139-162.

Gutiérrez Valencia, Cristina (2019). Procesos de configuración autorial en el Siglo de Oro: el caso de Lope de Vega. Tesis doctoral. Universidad de Oviedo.

Madroñal, Abraham (2000). «Glosario de voces comentadas relacionadas con el vestido, el tocado y el calzado en el teatro español del Siglo de Oro», Cuadernos de Teatro Clásico. 13-14, pp. 229-302.

Márquez Villanueva, Francisco (1998). Menosprecio de corte y alabanza de aldea (Valladolid, 1539) y el tema áulico en la obra de Fray Antonio de Guevara. Santander: Universidad de Cantabria.

Navarro Durán, Rosa (1997). «El arte de fingirse boba y otras recreaciones: La boba para los otros y discreta para sí», en Felipe B. Pedraza Jiménez y Rafael González Cañal (eds.), La década de oro en la comedia española 1630-1640. Almagro: Universidad de Castilla-La Mancha, pp. 41-59.

Oleza, Joan (2003). «El Lope de los últimos años y la materia palatina», Criticón. 87-89, pp. $603-620$.

Oleza, Joan (2004). «Las opciones dramáticas de la senectud de Lope», en José Ma Díez Borque y José Alcalá-Zamora (coords.), Proyección y significados del teatro clásico español: homenaje a Alfredo Hermenegildo y Francisco Ruiz Ramón. Madrid: SEACEX, pp. 257-276.

Profeti, Ma Grazia (1997). «El último Lope», en Felipe B. Pedraza Jiménez y Rafael González Cañal (eds.), La década de oro en la comedia española 1630-1640. Almagro: Universidad de Castilla-La Mancha, pp. 11-39.

Redondo, Augustin (1979a). «Du Beatus ille horacien au Menosprecio de Corte y Alabanza de Aldea d'Antonio de Guevara», en Augustin Redondo (ed.), L'humanisme dans les lettres espagnoles. Paris: Librairie Philosophique J. Vrin, pp. 251-265.

Redondo, Augustin (1979b). «Le Menosprecio de Corte d'Antonio de Guevara et l'Inquisition», Les cultures ibériques en devenir. Essais publiés en hommage à la mémoire de Marcel Bataillon (1895-1977). Paris: Fondation Singer-Polignac, pp. 189-196. 
Rozas, J.M. (1982). «Lope de Vega y Felipe IV en el ciclo de senectute». Discurso de apertura de curso 1982-83. Badajoz-Cáceres: Universidad de Extremadura. Accesible en: $<\mathrm{http} / /$ www.cervantesvirtual.com/obra-visor-din/lope-de-vega-y-felipe-iv-en-el-ciclode-senectute-0/html/ff8da5d0-82b1-11df-acc7-002185ce6064_14.html\#I_0_> [acceso: 7/2019]

Ruano de la Haza, José María (2000). La puesta en escena en los teatros comerciales del Siglo de Oro. Madrid: Castalia.

Rubiera, Javier (2005). La construcción del espacio en la comedia española del Siglo de Oro. Madrid: Arco/Libros.

Salomon, Nöel (1985). Lo villano en el teatro del siglo de Oro. Madrid: Castalia.

Sánchez Jiménez, Antonio (2006). Lope pintado por sí mismo: Mito e imagen del autor en la poesía de Lope de Vega Carpio. Londres: Tamesis Books.

Vega García-Luengos, Germán (2012). «Lope y Calderón: episodios de una rivalidad literaria y comercial», en Graciela Balestrino y Marcela Beatriz Sosa (eds.), Letras del Siglo de Oro español. Actas del VII Congreso LESOE. Salta: Universidad Nacional de Salta, pp. 61-76.

Wright, Elisabeth R. (2001). Pilgrimage to Patronage: Lope de Vega and the Court of Philip III, 1598-1621. Lewisburg, Pa.: Bucknell University Press.

Zugasti Zugasti, Miguel (2015). «Deslinde de un género dramático mayor: comedia palatina cómica y comedia palatina seria en el Siglo de Oro», Cuadernos de Teatro Clásico. 31, pp. 65-102.

Fecha de recepción: 19 de diciembre de 2016.

Fecha de aceptación: 12 de junio de 2017. 